Tersedia online di:http://ejournal-balitbang.kkp.go.id/index.php/jkpi
e-mail:jkpi.puslitbangkan@gmail.com
JURNAL KEBIJAKANPERIKANANINDONESIA
Volume 12 Nomor 1 Mei 2020
p-ISSN: 1979-6366
e-ISSN: 2502-6550
Nomor Akreditasi Kementerian RISTEKDIKTI: 21/E/KPT/2018

\title{
STATUS STOK UDANG JERBUNG (PENAEUS MERGUIENSIS) DI PERAIRAN BENGKALIS DAN SEKITARNYA SERTA KEMUNGKINAN PENGELOLAANNYA SECARA BERKELANJUTAN
}

\section{STOCK STATUS OF BANANA PRAWN (PENAEUS MERGUIENSIS) IN BENGKALIS WATERS AND ITS POSSIBILITY OF SUSTAINABLE MANAGEMENT}

\author{
Ali Suman ${ }^{\star 1}$, Duranta D. Kembaren ${ }^{1}$, Andina Ramadhani Putri Pane ${ }^{1}$ dan Muhammad Taufik ${ }^{1}$ \\ ${ }^{1}$ Balai Riset Perikanan Laut, Jalan Raya Bogor Km 47, Nanggewer Mekar, Cibinong, Jawa Barat-Indonesia \\ Teregistrasi I tanggal: 25 Februari 2020; Diterima setelah perbaikan tanggal: 28 Mei 2020; \\ Disetujui terbit tanggal: 02 Juni 2020
}

\begin{abstract}
ABSTRAK
Pemanfatatan sumber daya udang jerbung (Penaeus merguiensis) di perairan Bengkalis dan sekitarnya sudah berlangsung cukup lama dan dilakukan sangat intensif. Untuk menjaga kelestariannya, dibutuhkan opsi pengelolaan agar sumber daya ini dapat dimanfaatkan secara berkelanjutan. Tujuan penelitian ini adalah untuk mengkaji status stok dan kemungkinan pengelolaan udang jerbung di perairan Bengkalis dan sekitarnya. Penelitian dilakukan pada periode survei 2013-2017 dengan metode survei dan diperkaya dengan sintesis hasil-hasil penelitian di perairan Bengkalis. Hasil analisis menunjukkan bahwa struktur ukuran udang berkisar antara 12$58 \mathrm{~mm}$ dengan perbadingan kelamin didominasi udang betina, sementara pola pertumbuhannya bersifat allometrik negatif. Ukuran udang jerbung yang tertangkap pada umumnya belum memijah. Laju pertumbuhan (K) udang jerbung sebagai 1,0/tahun dengan panjang karapas maksimum ( $\left.\mathrm{L}_{\infty}\right)$ $58,1 \mathrm{~mm}$. Laju kematian total $(Z)$ dan laju kematian alamiah (M) masing-masing 5,43/tahun dan 1,51/tahun. Laju kematian karena penangkapan (F) sebagai 3,92/tahun dan laju pengusahaan (E) sekitar 0,72/tahun, sementara spawning potential ratio (SPR) adalah $8 \%$. Dengan demikian status stok udang jerbung sudah berada pada penangkapan berlebih (overfishing). Untuk menjamin kelestariannya, maka perlu dilakukan opsi-opsi pengelolaan meliputi penutupan daerah/musim penangkapan pada bulan April, melakukan pengurangan upaya penangkapan sekitar $44 \%$ dari kondisi saat ini dan penetapan ukuran udang jerbung terkecil yang boleh ditangkap yaitu pada ukuran panjang karapas $29,8 \mathrm{~mm}$.
\end{abstract}

Kata Kunci: Pengelolaan; status stok; udang jerbung; perairan Bengkalis; WPP NRI 571

\begin{abstract}
The exploitation level of banana prawn (Penaeus merguiensis) resources in Bengkalis and surrounding waters has been done very intensive for a long time and until now. To preserve the banana prawn resources, it needs management options to sustain the use of these resources. The aim of this study was to identify the stock status and management of banana prawn in Bengkalis and surrounding waters. The research was conducted during 2013 to 2017 using survey methods and supplemented by the synthesis of investigation results from Bengkalis waters. Results show that the prawn's size structure ranged between $12-58 \mathrm{~mm}$, the sex ratio was dominated by female and the growth pattern was negative allometric. Most of the prawn were caught in immature condition. The growth rate $(K)$ was 1.0/year with maximum carapace length $\left(L_{\infty}\right)$ of $58.1 \mathrm{~mm}$. Total mortality $(Z)$ and natural mortality (M) was 5.43/year and 1.51/year respectively. The fishing mortality $(F)$ was at 3.92/ year and exploitation level (E) was around 0.72/year, while the spawning potential ratio (SPR) was $8 \%$. Hence the banana prawn stock in Bengkalis and surrounding waters is in overfishing condition. Management options are proposed in order to keep the sustainability of the resources, such as:
\end{abstract}


closed area/season in April, reducing effort to $44 \%$ from current condition, and legal size catch limitation at 29,8 $\mathrm{mm}$.

Keywords: Management; stock status; banana prawn; Bengkalis waters; Indonesian FMA 571

\section{PENDAHULUAN}

Indonesia mempunyai daerah penangkapan udang yang cukup potensial yang menyebar hampir di sebagian besar perairan pantai Indonesia. Perairan yang cukup potensial meliputi Pantai Barat Sumatera (Aceh dan Sumatera Barat), sepanjang Pantai Timur Sumatera dan Selat Malaka (Aceh, Sumatera Utara dan Riau), Pantai Utara Jawa, Pantai Selatan Jawa, Perairan Kalimantan (Kalimantan Barat dan Timur), Sulawesi (Sulawesi Selatan) dan perairan Maluku-Irian Jaya (Naamin et al., 1992). Semakin meningkatnya permintaan udang jerbung untuk tujuan ekspor dan konsumsi dalam negeri, mengakibatkan tekanan penangkapannya semakin intensif dan dikhawatirkan akan mengganggu kelestarian sumber daya ini (Suman et al., 2018b). Perairan Bengkalis merupakan bagian Wilayah Pengelolaan Perikanan Negara Republik Indonesia Selat Malaka dan Laut Andaman (WPPNRI 571), yang terletak di pantai timur Sumatera, termasuk pada kawasan dengan status pemanfaatan sumber daya udang yang sudah berada dalam tahapan overfishing (Suman et al., 2018b), sehingga perlu dilakukan analisis yang lebih menyeluruh terutama status stok sumberdayanya.

Sumber daya udang termasuk sumber daya yang dapat pulih (renewable resources), walaupun demikian penangkapan yang terus meningkat tanpa adanya pembatasan akan menyebabkan habisnya sumber daya tersebut. Tingginya intensitas penangkapan di perairan Bengkalis ini (BPPL, 2016), yang dilakukan setiap hari sepanjang tahun, dikhawatirkan akan mengancam kelestarian dan keberlanjutan sumber daya udang di perairan ini. Hal ini telah terindikasi dengan terjadinya penurunan indeks kelimpahan,

Tabel 1. Struktur ukuran udang jerbung (P. merguiensis) di berbagai perairan

Table 1. The size structure of banana prawn (P. merguiensis) in several waters padahal di lain pihak terjadi kenaikan jumlah upaya penangkapan (BPPL, 2016). Dalam kaitan ini, Naamin (1984) menyatakan bahwa penambahan jumlah upaya penangkapan pada batas tertentu dapat menyebabkan peningkatan produksi, tetapi apabila terus terjadi penambahan upaya maka pada suatu saat akan terjadi penurunan stok.

Apabila pola pengelolaan sumber daya udang yang ada saat ini tetap berjalan, maka dalam jangka panjang akan dapat menyebabkan sumber daya udang di perairan Bengkalis dan sekitarnya terancam mengalami kepunahan. Melihat fenomena tersebut maka di perairan Bengkalis ini harus dilakukan upayaupaya pengelolaan sumber daya udang yang lebih baik, sehingga sumber daya udang yang ada dapat menjadi modal bagi perbaikan (recovery) stok (Monintja, 2000) dan dapat menjamin kelestarian sumber daya ini dalam jangka panjang (FAO, 1995).

\section{BAHASAN \\ Status Stok Udang Jerbung}

Struktur ukuran panjang karapas udang jerbung (Penaeus merguiensis) di perairan Bengkalis berkisar antara $12-58 \mathrm{~mm}$ dan dominan tertangkap pada ukuran panjang karapas 24-28 mm. Hasil ini berbeda dengan struktur ukuran jerbung di berbagai perairan (Tabel 1). Perbedaan struktur ukuran udang jerbung pada berbagai perairan tersebut disebabkan oleh adanya perbedaan kondisi oseanografi perairan (Motta et al., 2005). Selain itu juga bisa disebabkan oleh adanya perbedaan karasteristik masing-masing spesies dan tekanan penangkapan (Thorson, 1983; Kembaren \& Nurdin, 2015).

\begin{tabular}{lcl}
\hline Lokasi/Location & $\begin{array}{l}\text { Kisaran Ukuran/ } \\
\text { Range (-mm-) }\end{array}$ & \multicolumn{1}{c}{ Sumber/Source } \\
\hline - Demak & $19,9-48,0 \mathrm{~mm}$ & Wedjatmiko \& Yulianti, (2003) \\
- Sampit & $18,0-58,0 \mathrm{~mm}$ & Nurdin \& Kembaren, (2015) \\
- Utara Jawa Tengah & $14,0-68,0 \mathrm{~mm}$ & Tirtadanu \& Ernawati, (2016) \\
- Tarakan & $19,0-53,0 \mathrm{~mm}$ & Chodrijah \& Suman, (2017) \\
- Kotabaru & $14,0-46,0 \mathrm{~mm}$ & Tirtadanu et al. (2017) \\
- Segara Anakan & $11,0-42,0 \mathrm{~mm}$ & Wagiyo et al. (2018) \\
\hline
\end{tabular}

Nisbah kelamin udang jerbung jantan dan betina di perairan Bengkalis adalah $1: 1,4$ dimana ditemukan jumlah jenis kelamin betina lebih besar. Hasil analisa dengan uji Chi-kuadrat (Walpole, 1993), menunjukkan bahwa perbandingan kelamin tersebut berada pada kondisi yang tidak seimbang. Fenomena yang sama 
ditemukan di perairan Demak (Wedjatmiko \& Yulianti, 2003), perairan Arafura (Hargiyatno et al., 2015), perairan Utara Jawa Tengah (Tirtadanu \& Ernawati, 2016), perairan Kotabaru (Tirtadanu et al., 2017) dan di perairan Segara Anakan (Wagiyo et al., 2018). Menurut Saputra et al. (2013), apabila jantan dan betina seimbang atau betina lebih banyak dapat diartikan bahwa populasi udang jerbung di perairan Bengkalis masih ideal untuk mempertahankan kelestariannya.

Hubungan panjang berat udang jerbung digunakan untuk melihat sifat pertumbuhannya. Hasil analisa menunjukkan bahwa persamaan hubungan panjang berat udang jerbung di perairan ini mengikuti rumus $\mathrm{W}=0,315 \times \mathrm{CL}^{1,18}$. (Ball \& Rao, 1984) dan uji t dengan tingkat kepercayaan 95\% (Walpole, 1993), menunjukkan bahwa sifat pertumbuhan udang jerbung adalah allometrik negatif. Hal ini menunjukkan bahwa pertumbuhan berat tidak sebanding dengan pertambahan panjang karapas, pertambahan panjang karapas lebih cepat daripada pertambahan bobot tubuh. Hasil ini sama didapatkan di perairan Demak (Wedjatmiko \& Yulianti, 2003), perairan Arafura (Hargiyatno et al., 2013), perairan Utara Jawa Tengah (Tirtadanu \& Ernawati, 2016), perairan Kotabaru (Tirtadanu et al., 2017) dan di perairan Segara Anakan (Wagiyo et al., 2018). Adanya perbedaan atau kesamaan pola pertumbuhan tersebut disebabkan model pertumbuhan individual bergantung pada ketersediaan makanan dan suhu perairan (Monterio, 2002 dalam Fauzi et al., 2013). Perbedaan pertumbuhan panjang juga dapat terjadi karena adanya perbedaan faktor eksternal dan faktor internal. Menurut Effendie, (2002), faktor internal adalah faktor yang umumnya sulit dikontrol seperti keturunan, jenis kelamin, umur dan penyakit. Sementara itu, faktor eksternal yang utama mempengaruhi pertumbuhan ikan adalah suhu dan makanan.
Musim pemijahan udang di suatu perairan dapat diketahui melalui pengamatan terhadap penyebaran densitas telur atau dapat pula melalui pengamatan tingkat kematangan gonad udang betina di perairan tersebut (Martosubroto, 1978; Tuma, 1967 dalam Naamin, 1984). Musim pemijahan udang jerbung di perairan Bengkalis terjadi sepanjang tahun dengan puncaknya pada bulan April. Hasil penelitian ini berbeda dengan penemuan di berbagai perairan. $\mathrm{Di}$ perairan Tanjung Krawang, puncak musim pemijahan udang jerbung didapatkan pada bulan Maret dan Desember (Martosubroto, 1978), sementara di perairan pantai utara Jawa Barat ditemukan pada bulan Maret dan April (Suman et al., 1991) dan di perairan Cilacap pada bulan Januari dan Pebruari (Khamdan, 2015). Perbedaan puncak musim pemijahan ini pada berbagai perairan kemungkinan disebabkan oleh lingkungan dan pola penambahan baru (Naamin, 1984).

Ukuran rata-rata udang jerbung yang tertangkap pertama kali (Lc) dan matang gonad ( $\mathrm{Lm}$ ) di perairan Bengkalis ditemukan pada panjang karapas $26,8 \mathrm{~mm}$ dan 27,1 mm (Sparre \& Venema, 1992; King, 1995). Hal ini menunjukkan bahwa rata-rata ukuran tertangkap lebih kecil daripada rata-rata ukuran matang gonad ( $\mathrm{LC}<\mathrm{Lm}$ ) dan mengindikasikan bahwa udang jerbung tersebut telah tertangkap terlebih dahulu sebelum mencapai ukuran matang kelamin. Kondisi ini jika terjadi secara terus menerus akan menyebabkan terjadinya degradasi stok karena jumlah rekrutmen udang akan semakin sedikit disebabkan oleh terhambatnya proses regenerasi. Hasil penelitian nilai Lm ini berbeda dengan yang ditemukan pada berbagai perairan (Tabel 2). Perbedaan ukuran nilai Lm pada berbagai perairan dipengaruhi oleh ketersediaan makanan dan kondisi lingkungan seperti suhu dan salinitas.

Tabel 2. Rata-rata ukuran matang gonad ( $\mathrm{Lm})$ udang jerbung ( $P$. merguiensis de Man) di berbagai perairan Table 2. Length at first maturity ( $\mathrm{Lm})$ of banana prawn (P. merguiensis de Man) in several waters

\begin{tabular}{ccc}
\hline Perairan/Waters & Lm (CL-mm) & Sumber/Source \\
\hline Bintuni Bay & 33.87 & Sumiono (1983) \\
Kupang and Belu & 41.80 & Suman \& Nugroho, (1991) \\
Demak & 39.77 & Suman \& Subani, (1994) \\
Dolak & 38.7 & Hargiyatno et al. (2013) \\
Tarakan & 33.8 & Kembaren \& Suman, (2013) \\
Arafura & 38,7 & Hargiyatno et al. $(2013)$ \\
Teluk Cenderawasih & 39,4 & Kembaren \& Ernawati, (2015) \\
Sampit & 38,7 & Nurdin \& Kembaren, (2015) \\
Utara Jawa Tengah & 42.85 & Tirtadanu \& Ernawati, (2016) \\
Cilacap & 38,3 & Suman \& Priosantoso, (2017) \\
Tarakan & 33,58 & Chodrijah \& Suman, (2017) \\
Kotabaru & 35,3 & Tirtadanu et al. (2017) \\
Segara Anakan & 17,15 & Wagiyo et al. (2018)
\end{tabular}


Pada dasarnya program ELEFAN digunakan untuk menginterpretasikan data frekuensi panjang karapas dengan cara melacak pergeseran modus sebaran frekuensi panjang karapas dalam suatu urutan waktu (time series) yang dicocokkan dengan kurva von Bertalanffy. Kurva yang melalui modus paling banyak akan menggambarkan pola pertumbuhan (Sparre \& Venema,1992). Nilai laju pertumbuhan (K) udang jerbung di perairan Bengkalis adalah 1,0 per tahun dan nilai panjang karapas maksimum $\left(\mathrm{L}_{\infty}\right)$ sesbesar $58,1 \mathrm{~mm}$. Nilai K udang jerbung yang lebih besar atau sama dengan 1 (satu) menunjukkan bahwa udang jerbung ini mempunyai laju pertumbuhan yang cepat (Gulland,1983; Naamin, 1984). Semakin rendah nilai K maka akan semakin lama suatu spesies mencapai nilai $L_{\infty}$, begitu juga sebaliknya (Sparre \& Venema, 1992). Dalam Tabel 3 disajikan nilai $K$ dan $L_{\infty}$ udang jerbung dari berbagai perairan.

Tabel 3. Laju pertumbuhan $(\mathrm{K})$ dan panjang karapas maksimum $\left(\mathrm{L}_{\infty}\right)$ udang jerbung ( $P$. merguiensis de Man) pada berbagai perairan

Table 3. The growth rate $(K)$ and maximum carapace length $\left(L_{\infty}\right)$ of banana prawn (P. merguiensis de Man) in several waters

\begin{tabular}{ccc}
\hline Perairan/Waters & $\mathbf{K}$ (per tahun) $\mathbf{L} \infty(\mathbf{m m})$ & Sumber/Source \\
\hline Arafura & $1,6250,2$ & Naamin, 1984 \\
Kotabaru & $1,444,3$ & Suman \& Umar, (2010) \\
Sampit & $1,4557,8$ & Kembaren \& Nurdin, (2013) \\
Teluk Cenderawasih & $1,0548,7$ & Kembaren \& Ernawati, (2015) \\
Cilacap & $1,1054,2$ & Suman \& Priosantoso, (2017) \\
Tarakan & $1,3357,6$ & Chodrijah \& Suman, (2017) \\
Tanah Laut & $1,0555,0$ & Suman et al. (2018a) \\
Segara Anakan & $1,4744,6$ & Wagiyo et al. (2018) \\
\hline
\end{tabular}

Dalam Tabel 3 tersebut terlihat parameter pertumbuhan ( $\mathrm{K}$ dan $\mathrm{L}_{\infty}$ ) berbeda pada berbagai perairan. Hal ini kemungkinan disebabkan oleh pengaruh kondisi lingkungan yang berbeda pada masing-masing perairan tersebut (Przybylski, 1996; Tsounami et al., 2006). Kondisi lingkungan tersebut meliputi ketersediaan makanan, suhu perairan, oksigen terlarut, ukuran ikan dan kematangan gonad (Jamal et al., 2011). Knaepkens et al. (2002) dan Effendie, (2002) menyatakan perbedaan nilai K dan $\mathrm{L}_{\infty}$ disebabkan oleh faktor internal/intrinsik dan faktor eksternal. Faktor internal yang berpengaruh tersebut meliputi keturunan, parasit dan penyakit, sementara faktor eksternal berupa suhu dan ketersediaan makanan.

Pada perikanan udang jerbung yang telah berkembang sangat intensif di perairan Bengkalis, laju kematian total (Z) sebesar 5,43 per tahun merupakan kombinasi dari laju kematian alamiah (M) sebesar 1,51 per tahun dan laju kematian karena penangkapan $(F)$ sebesar 3,92 per tahun (Sparre \& Venema, 1992, Gayanilo et al., 2005). Nilai M udang jerbung jantan di perairan Bengkalis terlihat lebih lebih kecil dibanding nilai F-nya dan hal ini menunjukkan bahwa sebagian besar udang jerbung di perairan Bengkalis mati karena penangkapan. Dengan demikian hal ini menunjukkan bahwa tekanan penangkapan udang jerbung sudah sangat intensif di perairan Bengkalis. Saputra \& Subiyakto, (2007) beserta peneliti lainnya menemuka laju kematian udang jerbung pada berbagai perairan (Tabel 4). Adanya perbedaan nilai laju kematian pada berbagai perairan disebabkan berbedanya jumlah upaya penangkapan dan kondisi lingkungan (Suman et al., 2017).

Tabel 4. Laju kematian total (Z), laju kematian alamiah (M) dan laju kematian karena penangkapan (F) per tahun udang jerbung (P. merguiensis de Man) di berbagai perairan

Table 4. The total mortality rate $(Z)$, natural mortality rate $(M)$ and fishing mortality $(F)$ per year of banana prawn (P. merguiensis de Man) in several waters

\begin{tabular}{clc}
\hline Perairan/Waters & Z M F & Sumber/Source \\
\hline Segara Anakan & 7.021 .965 .06 & Saputra \& Subiyakto, (2007) \\
Kotabaru & 4.521 .962 .56 & Suman \& Umar, (2010) \\
Bone & $7,861.905 .96$ & Kembaren et al. (2012) \\
Tarakan & 4.851 .763 .09 & Kembaren \& Suman, (2013) \\
Sampit & 5.701 .933 .77 & Nurdin \& Kembaren, (2015) \\
Teluk Cenderawasih & $4,961,683,28$ & Kembaren \& Ernawati, (2015) \\
Cilacap & $1,691,080,61$ & Suman \& Priosantoso, (2017) \\
Tarakan & $7,51,825,68$ & Chodrijah \& Suman, (2017) \\
Tanah Laut & $6,051,584,47$ & Suman et al., (2018a) \\
\hline
\end{tabular}


Dengan menggunakan nilai laju kematian karena penangkapan $(F)$ dan nilai laju kematian total $(Z)$ yang telah dihitung, didapatkan nilai laju pengusahaan $(E)$ udang jerbung di perairan Bengkalis adalah 0,72. Kriteria dari Pauly et al.(1984) menyebutkan bahwa nilai laju pengusahaan yang rasional dan lestari di suatu perairan berada pada nilai $\mathrm{E}<0,5$ atau paling tinggi pada nilai $E=0,5$. Dengan demikian terlihat laju pengusahaan sumber daya udang putih di perairan ini sudah berada pada tahapan penangkapan yang berlebih (over exploited). Apabila tidak dilakukan penataan laju pengusahaan yang ada saat ini, maka dikhawatirkan dalam jangka panjang akan mengakibatkan terancamnya kelestarian dan kesinambungan pemanfaatan sumber daya udang di perairan ini.

Metode Spawning Potential Ratio (SPR) digunakan pada data biologi dan parameter pertumbuhan udang jerbung. Hasil analisa data berdasarkan pendekatan yang dikenalkan oleh Prince, (2014) seperti yang disajikan pada Gambar 1, diperoleh bahwa pada saat mencapai ukuran matang gonad rasio potensi pemijahan udang jerbung di perairan Bengkalis sebesar $8 \%$ (SPR < 10\%). Hal ini menunjukkan bahwa berdasarkan kriteria Prince et al. (2015), kondisi stok udang jerbung cenderung mengarah pada kondisi penangkapan berlebih (overfishing). Rasio potensi pemijahan (Spawning Potential Ratio, SPR) atau disebut juga pemijahan per rekrut (Spawning Per Recruit) merupakan indeks reproduksi relatif yang umum digunakan untuk mengetahui kondisi stok pada perikanan yang sudah dieksploitasi (Mace \&
Sissenwine, 1993 dalam Prince et al., 2015; Walters \& Martell, 2004). Rasio potensi pemijahan didefinisikan sebagai proporsi potensi reproduksi yang tertinggal di alam setelah dilakukan eksploitasi dengan sejumlah tekanan penangkapan. Rasio potensi pemijahan udang jerbung di perairan Bengkalis ini sudah berada dibawah ambang batas potensi lestari yaitu $8 \%$ (SPR < 10\%) (Gambar 1). Penilaian ini berdasarkan kriteria SPR yang dikemukakan oleh Prince et al. (2015) terhadap perikanan rajungan. Mengingat bahwa nilai referensi SPR untuk udang belum ada maka nilai referensi SPR udang disamakan dengan rajungan dengan pertimbangan bahwa umur maksimal dari kedua spesies ini cenderung sama. Ambang batas potensi pemijahan untuk jenis krustasea lain seperti lobster telah banyak dikemukakan. Untuk perikanan lobster bercapit, Homarus americanus di Amerika dan Kanada digunakan ambang batas SPR masing-masing sebesar 10\% dan 5\% (Caddy, 2004 dalam Prince et al., 2015). Ambang batas SPR untuk jenis-jenis lobster berduri, Panulirus sp. digunakan sebesar 20\% baik di perairan Karibia, Hawai maupun di perairan Autralis Barat (Miller \& Hannah, 2006 dalam Prince et al., 2015; Caputti et al., 1996 dalam Prince et al., 2015).

Berdasarkan kriteria tersebut diketahui bahwa status stok udang jerbung di perairan Bengkalis dan sekitarnya sudah mengarah pada penangkapan berlebih $(E>0,5 ;$ SPR $<10 \%)$. Persentase lebih tangkap udang jerbung di perairan Bengkalis sudah tergolong tinggi, maka upaya-upaya pengelolaan perikanan yang berkelanjutan harus diterapkan.



Gambar 1. Grafik persentase SPR terhadap panjang karapas udang jerbung di perairan Bengkalis.

Figure 1. The chart of SPR percentage of carapace length of banana prawn in Bengkalis waters. 


\section{Pengelolaan Sumber Daya Udang Secara Berkelanjutan}

Salah satu isu pokok mengenai penggunaan sumber daya alam adalah pertanyaan : "berapa lama dan dalam keadaan bagaimana kehidupan manusia dapat berlangsung terus di bumi ini dengan persediaan tertentu dari sumber daya yang melekat di suatu tempat (insitu resources), yang dapat diperbaharui tetapi dapat rusak, serta terbatasnya lingkungan hidup". Laporan kelompok Roma dalam "batas-batas pertumbuhan" menunjukkan kemungkinan dunia ambruk karena sumber daya yang penting (seperti bahan bakar minyak dan batubara) terbatas jumlahnya, sedangkan tingkat konsumsi dunia terus menerus meningkat. Beberapa sumber daya alam yang dapat diperbaharui (seperti perikanan dan sumber daya air) sedang mengalami kerusakan dan pencemaran, demikian pula kapasitas lingkungan dalam mengakomodasi limbah semakin terbatas. Sebagai gambaran, jika penggunaan sumber daya alam meningkat $5 \%$ per tahun, tingkat penggunaan itu meningkat menjadi dua kali lipat dalam waktu 14 tahun. Jika sekarang ini persediaan diketahui 100 kali penggunaan saat ini pula, maka persediaan sumber daya yang ada akan habis dalam waktu 36 tahun. Meskipun ada penemuan hebat dan membuat persediaan 200 kali penggunaan sekarang, persediaan itu akan habis dalam waktu 48 tahun (Suparmoko, 1997).

Menyadari keseriusan permasalahan pemanfaatan sumber daya perikanan dunia, maka Komisi Perikanan Dunia (The Committe on Fisheries) pada sidang yang kesembilan belas pada bulan Maret 1991 melakukan pengembangan konsep baru menuju perikanan yang bertanggung jawab dan berkelanjutan. Selanjutnya pada Konferensi Internasional tentang penangkapan ikan yang bertanggung jawab yang diselenggarakan pada tahun 1992 di Cancun, Mexico telah menunjuk FAO untuk mempersiapkan suatu konsep petunjuk pelaksanaan (code of conduct) untuk penangkapan ikan yang bertanggung jawab (responsible) dan memperhatikan prinsip-prinsip berkelanjutan (sustainability).

Pengelolaan sumber daya secara berkelanjutan (sustainable mangement) dalam perikanan (termasuk udang) timbul karena adanya isu global tentang terbatasnya sumber daya perikanan di satu pihak dan kebutuhan akan sumber daya perikanan yang terus meningkat akibat meningkatnya penduduk di lain pihak. Dengan menerapkan konsep pengelolaan sumber daya perikanan yang berkelanjutan maka akan dapat menyelamatkan sumber daya ikan tersebut dari kepunahan dan sekaligus menyelamatkan kepentingan kehidupan semua orang yang bergantung kepada sumber daya perikanan ini.

Pengelolaan sumber daya alam (udang jerbung) secara berkelanjutan adalah pemanfaatan sumber daya alam yang terbarui untuk kepentingan generasi sekarang dan yang akan datang dengan tetap menjaga kelestarikan sumber daya tersebut (Gilpin, 1996 dalam Suratmo, 2000). Sementara itu Dahuri, (2000) menyatakan bahwa pemanfaatan sumber daya alam secara berkelanjutan adalah suatu strategi pemanfaatan ekosistem alamiah sedemikian rupa, sehingga kapasitas fungsionalnya untuk memberikan manfaat bagi kehidupan manusia tidak rusak. Selanjutnya Monintja, (2000) menyatakan bahwa pemanfaatan sumber daya perikanan secara berkelanjutan mempunyai beberapa kriteria yaitu : (1) hasil tangkapan tidak melebihi jumlah yang boleh dimanfaatkan, (2) menggunakan bahan bakar lebih sedikit, (3) secara hukum alat tangkap legal, (4) investasi yang dibutuhkan rendah dan (5) produk mempunyai pasar yang baik.

Agar pemanfaatan sumber daya udang ini dapat dilakukan secara berkelanjutan, maka sumber daya ini harus dikelola secara rasional. Oleh karena itu sumber daya udang jerbung ini harus dikelola mulai dari tingkat awal pemanfaatannya sehingga diperoleh keseimbangan antara pengembangan dan keuntungan yang optimal. Dalam konteks ini kita dianjurkan untuk mengidentifikasikan tujuan-tujuan pengelolaan dan selanjutnya menentukan metode yang paling sesuai untuk itu. Dalam menentukan langkah-langkah pengelolaan maka harus didasarkan pada bukti ilmiah yang akurat (FAO, 1995)

Secara lebih khusus, sasaran pengelolaan perikanan udang biasanya dapat dikuantifikasikan dalam bentuk-bentuk keuntungan-keuntungan sosial berupa produksi makanan, nilai kotor bersih, kesempatan kerja, pendapatan individu nelayan, atau kombinasi dari hal-hal tersebut serta mempertahankan stok sumber daya udang jerbung pada tingkat produksi lestari yang tinggi. Objektifnya biasanya untuk mencapai keseimbangan yang optimum antara masukan-masukan dan berbagai pengeluaran. Karena perikanan udang jerbung terus berkembang dan kebutuhan masyarakat serta nilai uang selalu berubah, maka sasaran pengelolaan juga berubah.

Berbagai macam peraturan dan undang-undang telah dikeluarkan untuk pengelolaan dan pemanfaatan perikanan yang berkelanjutan untuk melindungi sumber daya tersebut dari kelebihan tangkap dan kepunahannya. Menurut Gulland, (1972) pada 
prinsipnya metode-metode pengelolaan tersebut digolongkan menjadi dua bagian yaitu pengontrolan ukuran udang yang tertangkap dan pengontrolan jumlah penangkapan (amount of fishing).

\section{Penutupan Daerah dan Musim Penangkapan}

Tindakan ini terutama dimaksudkan untuk memelihara siklus pertumbuhan udang, agar tidak terjadi pemutusan terhadap siklus yang dapat mengakibatkan penurunan populasi dan kepunahan satu atau beberapa jenis udang. Tindakan ini terutama ditujukan untuk membatasi efisiensi penangkapan, dan hanya akan efektif bila dilakukan secara simultan dengan pembatasan terhadap ukuran, jumlah serta kekuatan mesin kapal.

Penutupan musim penangkapan tidak boleh berjalan terlalu lama, sebab akan menimbulkan masalah ketenagakerjaan bagi nelayan yang mata pencahariannya tergantung sepenuhnya pada kegiatan penangkapan. Penutupan daerah penangkapan merupakan salah satu faktor yang mempunyai pengaruh relatif terbatas terhadap pembatasan upaya penangkapan. Penerapan tindakan ini pada umumnya dapat berupa penutupan terhadap berlakunya suatu jenis alat tangkap tertentu, misalnya trawl pada kedalaman atau jarak tertentu dari pantai. Dalam prakteknya, pelaksanaan peraturan penutupan daerah penangkapan kadang-kadang akan merupakan problema yang sulit diatasi tanpa adanya patroli/pengawasan yang efisien.

\section{Pembatasan Ukuran Udang Terkecil}

Pengontrolan ukuran udang pada saat pertama kali ditangkap dengan menentukan ukuran minimum yang boleh didaratkan ternyata kurang efektif dan telah merangsang praktek-praktek memusnahkan dan membuang kembali ke laut ikan-ikan yang ukurannya di bawah ukuran yang telah ditentukan. Walaupun demikian, peraturan tersebut dapat membantu dalam menegakkan peraturan lain seperti penutupan daerah penangkapan. Peraturan ini mungkin akan lebih efektif jika pemasaran udang yang berukuran di bawah minimum yang telah ditetapkan juga dilarang (Gulland, 1972).

\section{Pengaturan Ukuran Mata Jaring}

Pengaturan ukuran mata jaring dimaksudkan untuk meloloskan individu-individu udang yang berukuran kecil (muda) dari suatu stok. Jika pengaturan ukuran mata jaring telah menjadi pilihan, beberapa faktor berikut perlu dicoba. Termasuk diantaranya selektivitas (pengaruh tipe jaring dan benang yang berbeda dan ukuran hasil tangkap serta waktu penarikan), pendugaan pengaruh jangka pendek dan jangka panjang dan penentuan efektivitas penegakan peraturan.

\section{Pembatasan Jumlah Penangkapan}

Berbagai metode telah dicoba untuk mengurangi kematian karena penangkapan, tetapi tingkat keberhasilannya cukup bervariasi. Termasuk ke dalam cara pembatasan jumlah penangkapan ini adalah mempersingkat musim penangkapan, mengurangi daerah penangkapan yang dibuka, menggunakan alat dan metode yang kurang efisien, penentuan kuota hasil tangkapan, pembatasan jumlah kapal atau izin penangkapan dan pembatasan modal.

Karena kelimpahan stok sangat bervariasi (yang tergantung faktor lingkungan), manajer pengelolaan harus diberi informasi peramalan terakhir jika ia harus mengontrol tekanan penangkapan dan mencegah kelebihan tangkap penambahan baru (recruitment over-harvest). Manajer pengelolaan juga harus cepat menyadari setiap perubahan dari upaya penangkapan atau praktek-praktek lain yang mungkin mempengaruhi total hasil tangkapan. Manajer pengelolaan harus mempertimbangkan dampak sosial-ekonomi karena pengurangan efisiensi nelayan terutama selama periode meningkatnya biaya operasional dan pengolahan (Christmas, 1981).

\section{Pembatasan Alat Penangkapan}

Hasil tangkap dapat dikurangi dengan membatasi efisiensi unit penangkapan yang ada dengan syarat nelayan tidak meningkatkan upaya penangkapannya. Metode yang biasa digunakan adalah pembatasan ukuran trawl atau melarang penggunaan trawl di daerah tertentu.

Thailand telah melarang penggunaan trawl bermesin pada perairan sejauh $3.000 \mathrm{~m}$ dari pantai (Srikmuda, 1981). Di seluruh perairan Indonesia penggunaan trawl telah dilarang untuk melindungi nelayan tradisional. Tindakan tersebut sudah tentu memberikan dampak sosial ekonomi yang besar.

\section{Kuota Penangkapan}

Walau kuota terhadap total hasil tangkapan tahunan sering dilakukan untuk hewan air yang umurnya panjang (ikan paus, halibut, cod, udang Pandalid), tetapi kuota terhadap hasil tangkapan udang tidak begitu cocok. Karena umurnya pendek, kuota tahunan tidak akan mengontrol kematian penangkapan, bahkan mungkin akan merangsang 
nelayan untuk menangkap secara intensif pada waktu musim penangkapan karena khawatir jangka waktu kuota sangat singkat.

Pembatasan hasil per kapal per hari atau per trip dapat mengurangi mortalitas. Cara ini dilakukan pada beberapa perairan pantai di teluk Meksiko-Amerika Serikat untuk membatasi penangkapan yuwana udang. Hal ini memerlukan tingkat pemantauan yang tinggi agar penegakan hukum dapat efektif.

\section{Pembatasan Upaya Penangkapan}

Walau metode pengelolaan lain seperti kuota penangkapan dapat mencapai maksud-maksud biologi, tapi kontrol langsung terhadap upaya penangkapan (atau kapasitas armada penangkapan) kelihatannya masih perlu untuk merealisasikan keuntungan ekonomi yang nyata yang dapat diperoleh dari pengelolaan yang efektif. Metode ini kelihatannya juga dapat memberikan cara pengalokasian sumber daya diantara kelompok pemakai yang berbeda-beda.

Kriteria yang harus dipertimbangkan dalam menetapkan suatu tingkat upaya penangkapan tertentu adalah mempertahankan stok pada tingkat produktivitas yang ditentukan, menekan biaya seminimum mungkin, dan memperoleh dukungan dari nelayan yang diatur. Beberapa cara yang dapat membatasi upaya penangkapan adalah kuota, pembatasan izin penangkapan, pelaksanaan undangundang perikanan, penetapan pajak serta biaya izin penangkapan yang tinggi. Kuota penangkapan selain tidak menguntungkan seperti disebutkan di atas juga memerlukan tingkat penegakan hukum dan pengawasan yang tinggi agar efektif terutama pada perikanan skala besar.

Pada beberapa negara yang telah maju sistem pengelolaannya seperti Australia telah menerapakan beberapa hal di atas untuk pemanfaatan sumber daya udangnya secara berkelanjutan (Bowen \& Hancock, 1985). Langkah-langkah pengelolaan yang dilakukan meliputi:

1. Pembatasan jumlah kapal

2. Penutupan daerah penangkapan secara permanen

3. Penutupan daerah penangkapan secara temporal atau musiman

4. Penutupan musim

5. Penutupan fase bulan

6. Ukuran udang minimum yang diizinkan

7. Pengaturan ukuran mata jaring

8. Karakteristik kapal

9. Pengaturan alat tangkap

10.Skema "buy-back"
Penutupan daerah penangkapan secara permanen adalah melindungi habitat daerah asuhan dari kerusakan akibat trawl. Dengan demikian recovery dari sumber daya udang akan terjamin. Sedangkan penutupan daerah penangkapan secara musiman dilakukan pada daerah konsentrasi udang muda, sehingga memberi kesempatan kepada udang tersebut tumbuh sesuai dengan ukuran pasar. Sementara itu penutupan musim dilakukan dengan berbagai alasan. Di Australia Selatan hal tersebut dilakukan untuk membatasi total waktu yang ada untuk penangkapan dan sekaligus juga untuk membatasi peningkatan upaya yang nyata. Selain itu penutupan musim ini dilakukan berkenaan dengan waktu tertentu yang dirayakan seperti Easterdan hari natal. Penutupan musim di Teluk Shark dari 1 Nopember sampai dengan 1 Maret bertujuan untuk mengontrol armada yang ingin mengusahakan juvenile udang.

Langkah-langkah pengelolaan udang yang lainnya dilakukan di Teluk Meksiko (Leary, 1985). Teknik yang digunakan adalah menunda panen sepanjang musim dan penutupan daerah penangkapan sehingga memberi kesempatan prerecruituntuk menjadi besar sesuai dengan ukuran yang diinginkan. Efektivitas dari peraturan Federal sangat tergantung kepada koordinasi dari pengelolaan dan penegakan hukum pada perairan pantai perbatasan. Manfaat dari pengelolaan Federal juga lebih didukung oleh kondisi lingkungan yang sesuai untuk menghasilkan lebih banyak prerecruit pada kawasan lindung Federal. Penutupan musim di sebelah barat teluk mengakibatkan kenaikan produksi Penaeus aztecus sekitar 9\% pada tahun 1981 dan 6 pada tahun 1982. Manfaat dari pengelolaan $P$. duodarum di timur teluk sangat sedikit diketahui dan hubungan dengan faktor lingkungan belum diketahui.

\section{Kemungkinan Pengelolaan Udang Jerbung Secara Berkelanjutan di Perairan Bengkalis}

Sumber daya udang dipandang sebagai sumber daya yang dapat pulih kembali (renewable resources), maka pengelolaan untuk menjamin keberlanjutan sumber daya tersebut harus diartikan sebagai upaya pemanfaatan sumber daya yang laju ekstrasinya tidak boleh melampaui laju kemampuan daya pulihnya. Status pemanfaatan sumber daya udang di perairan Bengkalis saat ini sudah berada pada tahapan overfishing dan hal ini menunjukkan bahwa kebijakan pengelolaan yang ada saat ini belum mampu menjamin kelestarian sumber daya. Oleh karena itu rezim pemanfaatan secara terbuka, sebagaimana yang umumnya dianut di Indonesia saat ini, sudah seharusnya tidak digunakan untuk mengusahakan 
sumber daya ini di perairan Bengkalis. Dalam kaitan itu perlu dilakukan perubahan paradigma pengelolaan menuju pemanfaatan berbasis unit stok dan kawasan dengan menerapkan opsi-opsi pengelolaan yang sesuai dengan hal tersebut. Untuk menentukan opsiopsi pengelolaan yang tepat tersebut, maka harus didasarkan pada hasil-hasil penelitian berupa aspek biologi, dinamika populasi, teknologi penangkapan dan sosial ekonomi.

Beragamnya jenis alat tangkap yang dipergunakan dan karakter sumber daya ikan tropis yang multispesies menyebabkan pengelolaan sumber daya udang jerbung di perairan Bengkalis menjadi tidak mudah untuk dilaksanakan. Namun demikian beberapa cara masih mungkin dapat dipilih sebagai opsi pengelolaan sumber daya udang jerbung tersebut, diantaranya: penutupan daerah dan musim penangkapan, pembatasan upaya penangkapan dan pembatasan ukuran udang terkecil yang boleh ditangkap (Gulland,1983).

\section{Penutupan Daerah dan Musim Penangkapan}

Bertujuan untuk melindungi udang muda dan juwana serta meningkatkan ukuran udang pertama kali matang kelamin dan akhirnya meningkatkan produksi. Dengan metode ini maka waktu yang krusial yang dibutuhkan oleh udang dalam siklus hidupnya, yaitu mulai memijah, menjadi larva dan menuju daerah asuhan dalam bentuk post larva, dapat terlindungi dan dengan demikian akan terjamin kelestarian sumber daya udang tersebut. Penutupan daerah dan musim penangkapan dapat dilakukan ketika udang mengalami puncak pemijahan. Dalam kaitan tersebut penutupan musim penangkapan udang jerbung di perairan Bengkalis sebaiknya dilakukan pada bulan April.

\section{Pembatasan Upaya Penangkapan}

Dilakukan dengan penataan jumlah upaya yang ada. Disarankan untuk mengurangi jumlah upaya pemanfaatan udang jerbung di periran Bengkalis sekitar $44 \%$ dari jumlah upaya yang ada saat ini.

\section{Pembatasan Ukuran Udang Jerbung Terkecil yang Boleh Ditangkap}

Dimaksudkan untuk melindungi udang agar dapat melakukan pemijahan sebelum tertangkap. Dengan demikian udang tersebut dapat melakukan pembaruan populasi, sehingga keberlanjutan dan kelestarian stok masih dapat terjamin. Ukuran udang jerbung terkecil yang boleh ditangkap di perairan Bengkalis adalah pada ukuran panjang karapas $29,8 \mathrm{~mm}$ dan hal ini akan mempertahankan SPR pada tingkatan $11,3 \%$

\section{KESIMPULAN DAN REKOMENDASI}

Struktur ukuran udang yang tertangkap didominasi ukuran panjang karapas 24-28 mm dengan perbandingan kelamin yang tidak seimbang. Pola pertumbuhan bersifat allometrik negatif yang menunjukkan pertambahan panjangnya lebih cepat dari pertambahan beratnya. Udang jerbung yang tertangkap pada umumnya belum memijah, sehingga dalam jangka panjang akan membahayakan kelestarian sumber daya. Udang jerbung mempunyai laju pertumbuhan yang cepat, umur yang pendek dan laju kematian yang cukup tinggi dan oleh karena itu harus berhati-hati dalam kebijakan pengelolaan dan pemanfaatannya. Pemanfaatan sumber daya ini sudah berlansung cukup lama di perairan Bengkalis dan status pemanfaatannya sudah berada dalam tahapan yang lebih tangkap (overfishing). Apabila keadaan ini terus berlangsung maka akan mengancam kelestarian dan keberlanjutan pemanfaatan sumber daya udang dan dalam jangka panjang akan menghancurkan usaha perikanan udang nasional. Dalam kaitan tersebut, maka perlu diterapkan opsi pengelolaan yang meliputi: (1) penutupan daerah/ musim penangkapan pada bulan April; (2) pembatasan upaya dengan melakukan pengurangan upaya $44 \%$ serta (3) pembatasan ukuran udang terkecil yang boleh ditangkap yaitu pada ukuran panjang karapas 29,8 $\mathrm{mm}$ dan hal ini akan dapat mempertahankan SPR pada tingkatan $11,3 \%$.

\section{DAFTAR PUSTAKA}

Ball, D.V., \& Rao, K.V. (1984). "Marine fisheries." New Delhi/ : Tata Mc. Graw-Hill Publishing Company Limited., 5-24 pp.

Bowen, B.K., \& Hancock, D.A. (1985). Review of penaeid prawn fishery management regimes in Australia. Second Australian National Prawn Seminar: p. 247-265.

BPPL (2016). Penelitian karakteristik biologi perikanan, habitat sumber daya dan potensi produksi di WPP-571. Laporan Akhir Balai Penelitian Perikanan Laut, Jakarta.

Chodrijah, U., \& Suman, A. (2017). Beberapa parameter populasi udang putih (Penaeus merguiensis de Man) di perairan Tarakan, Kalimantan Utara. BAWAL. 9 (2), 85-92. DOI: 10.15578/bawal.9.2.2017.85-92. 
Christmas, J.Y. (1981). The impact of environmental factors on the Gulf of Mexico shrimp stocks. Workshop on the Scientific Basis for the Management of Penaeid Shrimp, Florida, Nov. 1981: $21 \mathrm{p}$.

Dahuri, R. (2000). Kebijakan dan strategi pengelolaan pesisir dan laut dikaitkan dengan pengendalian pencemaran akibat kegiatan pertambangan. Makalah disajikan pada Semiloka tentang Pengendalian Pencemaran Laut Akibat Pertambangan. UNSRAT, Manado, 24 April 2000, p. 31.

Effendie, M. I. (2002). Fishery biology (p. 136). Yayasan Pustaka Nusatama, Yogyakarta.

FAO. (1995). Code of conduct for responsible fisheries. FAO, Rome.

Fauzi, M., Prasetyo, A.P., Hargiyatno, I.T., Satria, F.,m \& Utama, A.A. (2013). The relationship and condition factor of spiny lobster (Panulirus penicillatus) in waters of Gunung Kidul and Pacitan. Bawal, 5(2), 97-102. DOI: 10.15578/ bawal.5.2.2013.97-102.

Gayanilo, F. C. Jr., Sparre, P., \& Pauly, D. (2005). FAO-CLARM Stock Assessment Tools II (FiSAT II) (p. 168). Revised version.User's guide. FAO Computerized Information Series (Fisheries). No. 8, Revised version. FAO Rome.

Gulland, J.A. (1972). Some introductory guidelines to management of shrimp fisheries. FAO, IOFC/ DEV/72/74 : $12 \mathrm{p}$.

Gulland, J.A. (1983). Fish stock assessment (p. 223). A manual of basic methods. John Wiley \& Sons.

Hargiyatno, I.T, R.F. Anggawangsa \& B. Sumiono (2015). Sebaran spasio-temporal, ukuran dan densitas udang jerbung (Penaeus merguiensis de Mann, 1907) di sub area Dolak, Laut Arafura (WPPNRI 718). J.Lit.Perikan.Ind, 21(4), 261-269. DOI: 10.15578/jppi.21.4.2015.261-269.

Jamal, M., Muhammad, F.A.S., Haluan, J., \& Budi, W. (2011). Pemanfaatan data biologi ikan cakalang (Katsuwonis pelamis) dalam rangka pengelolaan perikanan bertanggung jawab di perairan Teluk Bone. Jurnal Natur Indonesia. 14(1): 107-111. DOI: 10.31258/jnat.14.1.107-113.

Kembaren, D.D., Sumiono, B., \& Suprapto. (2012). Biology and growth parameter of white shrimp
(Penaeus merguiensis) in South Sulawesi. In : Suman, A., Wudianto dan B. Sumiono (Eds.): Exploitation status of fishery resources in Makasar Strait, Bone Bay, Flores Sea and Banda Sea. IPB Press. Bogor. 300p.

Kembaren, D.D., \& Suman, A. (2013). Biology and population dynamics of banana shrimp (Penaeus merguiensis) in the Tarakan waters, East Borneo. Ind. Fish. Res. J.19(2), 99-105. DOI: 10.15578/ ifrj.19.2.2013.99-105

Kembaren, D.D., \& Nurdin, E. (2013). Dinamika populasi dan tingkat pemanfaatan udang windu (Penaeus monodon) di perairan Tarakan, Kalimantan Timur. J.Lit.Perik.Ind. 19(4), 221 226. DOI: 10.15578/jppi.19.4.2013.221-226.

Kembaren, D.D., \& Ernawati, T. (2015). Dinamika populasi dan estimasi rasio potensi pemijahan udang jerbung (Penaeus merguiensis de Man) di perairan Teluk Cendrawasih dan sekitarnya, Papua. J. Lit. Perikan.Ind. 21(3), 201-210. DOI: 10.15578/jppi.21.3.2015.201-210.

Khamdan, M.U. (2015). Population dynamic and exploitation level of banana prawn (Penaeus merguiensis) in Cilacap and surrounding waters. Thesis, Faculty of Natural Science and Mathematics, Post Graduate Program of Marine Science, University of Indonesia, Depok.

King, M. (1995). Fishery biology, assessment and management (p. 341). Fishing New Books United Kngdom.

Knaepkens, G., Knapen, D., Bervoets, L., Hanfling, B., Verheyen, E., \& Eens, M. (2002). Genetic diversity and condition factor : a significant relationship in Flemish but not in German populations of the the European bullhead (Cottus gobio L.). Heredity, 89(4): 280-287. DOI: 10.1038/ sj.hdy.6800133

Leary, T.R. (1985). Review of the Gulf of Mexico management plan for shrimp. Second Australian National Prawn Seminar: p. 267-273.

Martosubroto, P. (1978). Musim pemijahan dan pertumbuhan udang jerbung (Penaeus merguiensis de Man) dan udang dogol (Metapenaeus ensis de Haan) di perairan Tanjung Krawang. Prosiding Seminar ke-II Perikanan Udang: p. 7-20.

Monintja, D.R. (2000). Prosiding pelatihan untuk pengelolaan wilayah pesisir terpadu. Pusat Kajian 
Sumber Daya Pesisir dan Lautan, IPB Bogor, hal. 45-57.

Motta, F. S., Gadig, O.B.F., Namora, R.C., \& Braga, F. M.S. (2005). Size and sex compositions, length weight relationship, and occurrence of the Vrazilian sharpnose shark, Rhizoprionodon lalandii, caught by artisanal fishery from southeastern Brazil. Fisheries Research. 74 (2005). 116 - 126. DOI: 10.1016/j.fishres.2005.03.010.

Naamin, N. (1984). Dinamika populasi udang jerbung (Penaeus merguiensis de Man) di perairan Arafura dan alternatif pengelolaannya. Disertasi Doktor. Fakultas Pasca Sarjana IPB: 281 hal.

Naamin, N., Sumiono, B., llyas, S., Nugroho, D., Iskandar, P.S. B., Barus, H.R., Badrudin, M., Suman, A., \& Amin, E.M. (1992). Pedoman teknis pemanfaatan dan pengelolaan sumber daya udang penaeid bagi pembangunan perikanan. Seri Pengembangan Penelitian Perikanan No. PHP/ $\mathrm{KAN} / \mathrm{PT} / 22 / 1992$. Badan Penelitian dan Pengembangan Pertanian : 86 hal.

Nurdin, E., \& Kembaren, D.D. (2015). Parameter populasi udang putih (Penaeus merguiensis) di Perairan Sampit dan Sekitarnya, Kalimantan Tengah. BAWAL 7(2),103-109. DOI: 10.15578/ bawal.7.2.2015.103-109

Pauly, D., Ingles, J., \& Neal, R. (1984). Application to shrimp stocks of objective methods for the estimation of growth, mortality and recruitment related parameters from length frequency data (ELEFAN I and II). In : Penaeid shrimp - their biology and management : 220-234. Fishing News Book Limited. Farnham-Surrey-England.

Prince, J. (2014). A technical report on an SPR@size assesment of blue swimmer crab fishery in South Sulawesi. Report Project to IMACS (Unpublished)

Prince, J., Victor, S., Kloulchad, V., \& Hordyk, A. (2015). Length based SPR assessment of eleven Indo-Pacific coral reef fish populations in Palau. Fish.Res 171, 42-58. DOI: 10.1016/ j.fishres.2015.06.008.

Przybylski, M. (1996). Variation in fish growth characteristics along a river course. Hydrobiology, 325, 39-46.

Saputra, S.W., \& Subiyanto (2007). Population dynamic of white shrimp (Penaeus merguiensis de Man 1907) in Segara Anakan waters, Cilacap,
Central Java . Ilmu Kelautan. Diponegoro University. Vol. 12 (3):157-166. DOI: 10.14710/ ik.ijms.12.3.157-166.

Saputra, S.W., Djuwito., \& Rutiyaningsih, A. (2013). Beberapa aspek biologi udang jerbung (Penaeus merguiensis) di Perairan Pantai Cilacap Jawa. Journal of Management of Aquatic Resources. 2(3). 47-55.

Sparre, P., \& Venema, S.C. (1992). Introduction to tropical fish stock assesment. Part I. Manual. FAO Fish. Tech. Pap. No. 306/1.

Srikmuda, P. (1981). Shrimp fisheries in the Gulf of Thailand. Workshop on the Scientific Basis for the Managemen of Penaeid Shrimp, Florida, Nov. $1981: 16 \mathrm{p}$.

Suman, A., Rijal, M., \& Sumiono, B. (1991). Beberapa parameter populasi udang jerbung (Penaeus merguiensis de Man) di perairan pantai utara Jawa Barat. Jurnal Penelitian Perikanan Laut No. 60, 20-26.

Suman, A., \& Nugroho, D. (1991). Beberapa aspek biologi udang putih (Penaeus merguiensis de Man) di perairan Kupang dan Belu, Nusa Tenggara Timur. Jurnal Penelitian Perikanan Laut No. 61, 20 - 26.

Suman, A., \& Subani, W. (1994). Penelitian beberapa aspek biologi udang jerbung (Penaeus merguiensis de Haan) di perairan Demak, Jawa Tengah. Jurnal Penelitian Perikanan Laut No. 91, 64 - 71.

Suman, A., \& Umar, C. (2010). Dinamika populasi udang putih (Penaeus merguensis de Man) di perairan Kotabaru, Kalimantan Selatan. J.Lit.Perikan.Ind. 16(1), 29-33. DOI: 10.15578/ jppi.16.1.2010.29-33.

Suman, A., \& Prisantoso, B.I. (2017) Karakteristik populasi udang jerbung (Penaeus merguiensis de Man, 1888) di perairan Cilacap dan sekitarnya. $J$. Lit. Perikan.Ind. 23 (1), 11-18. DOI: 10.15578/ jppi.23.1.2017.11-18.

Suman, A., Hasanah, A., Ernawati, T., \& Pane, A.R.A. (2017a). The population dynamic of banana prawn (Penaeus merguiensis de Man) in Tanah Laut waters, South Kalimantan. Ind. Fish. Res. J. 23(1), 17-22. DOI: 10.15578/ifrj.23.1.2017.17-22.

Suman, A., Satria, F., Nugraha, B., Priatna, A., Amri, K., \& Mahiswara (2018b). Status stok sumberdaya ikan tahun 2016 di Wilayah Pengelolaan Perikanan Negara Republik Indonesia (WPP NRI) dan 
alternative pengelolaannya. J. Kebijak. Perikan. Ind. 10(2), 107-128. DOI: 10.15578/ jkpi.10.2.2018.107-128.

Sumiono, B. (1983). Ukuran matang dan perbandingan kelamin udang jerbung (Penaeus merguiensis de Man) di perairan Teluk Bintuni, Irian Jaya. Laporan Penelitian Perikanan Laut No. 29, 41-46.

Suparmoko, M. (1997). Ekonomi sumber daya alam dan lingkungan (Suatu pendekatan teoritis) (p. 568). Edisi 3, BPFE Yogyakarta.

Suratmo, F.G. (2000). Penerapan Undang-Undang No. 23 tentang pengelolaan lingkungan hidup dalam perencanaan pembangunan. IPB Bogor.

Thorson, T. B. (1983). Observations on the morphology, ecology, and life history of the euryhaline stingray, Dasyatis guttata (Bloch and Schneider) 1801. Acta Biologica Venezuelica. 11. $95-125$.

Tirtadanu., \& Ernawati, T. (2016). Kajian biologi udang jerbung (Penaeus merguiensis de Man, 1888) di perairan utara Jawa Tengah. BAWAL 8(2), 109116. DOI: 10.15578/bawal.8.2.2016.109-116.

Tirtadanu, Suprapto., \& Suman, A. (2017). Sebaran frekuensi panjang, hubungan panjang-berat, tingkat kematangan gonad dan rata-rata ukuran pertama kali matang gonad udang putih (Penaeus merguiensis de Man) di perairan Kotabaru, Kalimantan Selatan. BAWAL. 9(3), 145-152. DOI: 10.15578/bawal.9.3.2017.145-152.
Tsounami, M., Liaska, R., Mousaki, P., I. Kagalao \& I. Leonardos (2006). Length-weight relationship of an invasive cyprinid (Carassius gibelio) from 12 Greek Lake in relation to their trophic states. Journal Applied Ichtyologi, 22 : 281-284. DOI: 10.1111/j.1439-0426.2006.00768.x

Wagiyo, K., Damora, A., \& Pane, A.R.P. (2018). Aspek biologi, dinamika populasi dan kepadatan stok udang jerbung (Penaeus merguiensis de Man, 1888) di habitat asuhan estuari Segara Anakan, Cilacap. J. Lit. Perikan.Ind. 24(2), 127-136. DOI: 10.15578/jppi.24.2.2018.127-136.

Walpole, R.V.E. (1993). Pengantar statistik (p. 321). Terjemahan B. Sumantri (Edisi Tiga). PT. Gramedia. Jakarta.

Walters, C. J., \& Martell, S.J.D. (2004). Fisheries ecology and management. Princeton University Press, Princeton, USA. 448 pp.

Wedjatmiko., \& Yulianti (2003). Beberapa aspek biologi udang jerbung (Penaeus merguiensis) di perairan Mayangan, pantai utara Jawa Barat. J. Lit. Perikan. Ind. Edisi Sumber Daya dan Penangkapan, 9(3), 27-34. DOI: 10.15578/ jppi.9.3.2003.27-34. 